\title{
Protein Transport Protein Sec16A
}

National Cancer Institute

\section{Source}

National Cancer Institute. Protein Transport Protein Sec16A. NCI Thesaurus. Code C101474.

Protein transport protein Sec16A (2179 aa, $234 \mathrm{kDa}$ ) is encoded by the human SEC16A gene. This protein is involved in the regulation of intracellular protein transport. 